\title{
KAJIAN IMPLEMENTASI NILAI EMP SEPEDA MOTOR 0.15 BERDASARKAN HASIL PEMODELAN MIKROSIMULASI LALULINTAS UNTUK PERHITUNGAN KINERJA SIMPANG BERSINYAL
}

\author{
Supoyo ${ }^{1}$, lin Irawati $^{2}$ \\ Jurusan Teknik Sipil Fakultas Teknik Universitas Semarang (USM) Jalan Arteri Sukarno Hatta- \\ Semarang \\ Email : iin.irawati5477@gmail.com
}

\begin{abstract}
Idonesia Highway Capacity Manual 1997 was a product of a research analysis forming wich the parameter values are not absolute, but according to the characteristics of the existing traffic. IHCM 1997 considered no longer relevant to the current traffic conditions. In certain circumstances the analysis of IHCM 1997 does not correspond to field conditions, so IHCM 1997 needs a repair or revision. To repair IHCM 1997 also include the amount of PCE. This study only includes studies of PCE at signalized intersections with the development of methods headway through traffic simulation model with tools such as computer programs. In making the traffic simulation model for PCE, it is necessary to build an algorithm based on the theory - the theory of headway in the PCE are tailored to the features of the selected tool.Intersections are part of the road network. Inaccuracy in data analysis will affect results. The number 0.25 in IHCM 1997 in PCE is considered irrelevant, so an update number of 0.15 is used. From the results of data analysis was close to field conditions. The figure is derived from a modelS adapted to heterogeneous traffic flow. One of the characteristics of heterogeneous traffic is undisciplined. 0.15 is considered to represent the traffic conditions.
\end{abstract}

Keywords : PCE; motorcycle; IHCM; signal intersection; queue length.

Abstrak

Manual Kapasitas Jalan Indonesia 1997 adalah sebuah produk penelitian yang dibentuk dari hasil analisis data tahun 1994, yang mengacu pada kondisi lalulintas saat itu. MKJI 1997 seharusnya didasarkan pada kondisi arus lalulintas yang relevan. Pada kenyataannya, kondisi tersebut tidak sesuai dengan hasil lapangan, sehingga MKJI 1997 diperlukan suatu revisi. Salah satu subastansi yang direvisi adalah besaran nilai EMP. Penelitian ini bertujuan untuk mengakaji implementasi hasil peneitian pada EMP sepeda motor pada simpang bersinyal, menggunakan metode simulasi lalulintas dengan bantuan software. Untuk membangun model simulasi lalulintas, diperlukan adanya suatu algoritma program. Angka 0.25 dalam MKJI 1997pada EMP sepeda motor dianggap tidak relevan dengan kondisi yang ada. Jadi diperlukan updating nilai. Dari hasil penelitian yang sudah dilakukan, didapatkan angka 0.15. Angka tersebut diimplementasikan dalam Metode MKJI 1997.

Kata kunci : Ekivalen Mobil Penumpang; sepeda motor; MKJI, simpang bersinyal, panjang antrian.

\section{PENDAHULUAN}

Ketepatan evaluasi kapasitas pada simpang bersinyal merupakan komponen penting dalam perencanaan, desain, operasional serta manajemen terhadap jaringan jalan perkotaan. Dalam analisis dibutuhkan suatu pedoman atau manual yang relevan dengan kondisi lalulintas yang ada. Manual yang digunakan sebagai analisis, perencanaan dan perancangan lalulintas di Indonesia sekarang ini adalah Manual Kapasitas Jalan Indonesia (MKJI) 1997. 
Kondisi lalu lintas pada saat MKJI 1997 disusun dengan kondisi lalulintas sekarang tentu mengalami perubahan yang signifikan. Perubahan - perubahan tersebut adalah sebagai berikut :

1) Perubahan jumlah dan komposisi kendaraan bermotor.

Pada tahun 1987 sampai dengan tahun 1994 jumlah kendaraan bermotor yang terdaftar adalah 11.928.837 juta kendaraan, sedangkan pada tahun $1995-2013$ tercatat 104.118.969 (Badan Pusat Statistik,2014). Angka tersebut menunjukkan bahwa pada tahu 1994 sampai 2013 terdapat kenaikan jumlah kendaraan sebesar 92.190.632.

2) Perubahan panjang jalan Nasional ( geometrik jalan )

Jalan Nasional pada tahun 1990 - 1994 memiliki panjang $327.000 \mathrm{~km}$. Pada tahun 2011 panjang jalan Nasional adalah 437.700 km (Iskandar, 2011). Angka tersebut mengidentifikasikan bahwa terdapat perkembangan panjang jalan Nasional sebesar $34 \%$ dibanding tahun 1990 - 1994.

3) Teknologi kendaraan

Kendaraan-kendaraan baru banyak memiliki kemampuan yang lebih dari kendaraankendaraan sebelum tahun 1994, diantaranya kemampuan mesin yang lebih responsif, rem yang lebih handal, pengoperasian kendaraan yang lebih mudah misalnya dengan bertambahnya penggunaan transmisi otomatik, sehingga kemampuan manuver kendaraan lebih baik (Iskandar, 2011).

4) Perubahan perilaku pengemudi.

Salah satu tindakan agresif yang sering terjadi di jalan adalah manuver kendaraan saat menyiap, terutama manuver sepeda motor. Suatu perilaku pengemudi dikatakan agresif apabila dilakukan dengan sengaja yang dapat meningkatkan resiko kecelakaan dan dimotivasi oleh ketidaksabaran, kekesalan, permusuhan dan upaya menghemat waktu (Tasca, 2000). Peningkatan agresifitas pengemudi dapat diketahui dengan salah satu indikator yang berupa tingkat kecelakaan lalulintas. BPS (2014) mencatat bahwa pada tahun 1992 sampai 1994 terjadi kasus kecelakaan dari korban yang mengalami luka ringan hingga meninggal dunia sebesar 17.469, sedangkan pada tahun 1995 sampai 2013 tercatat 100.106 kecelakaan, sehingga terjadi kenaikan dari tahun 1994 sampai 2013 sebesar 82.637 kecelakaan. Angka tersebut menunjukkan bahwa terjadi perubahan perilaku pengemudi yang signifikan dari tahun 1994 hingga tahun 2013.

Berdasarkan perubahan - perubahan tersebut, maka MKJI 1997 dianggap sudah tidak relevan dengan kondisi existing lalulintas yang ada dan tidak tepat sebagai manual untuk analisis kapasitas simpang bersinyal, sehingga diperlukan suatu revisi atau perbaikan.

\section{METODOLOGI}

Metode penelitian yang dilakukan meliputi tahapan berikut ini :

1. Tahap ke-1 merupakan tahap awal penelitian yang berupa kegiatan observasi untuk mencari permasalahan dalam MKJI 1997 tentang analisis kapasitas simpang bersinyal.

2. Tahap ke-2 dari penelitian ini adalah menyusun kerangka berpikir, membuat identifikasi terhadap faktor, variabel,indikator serta parameter yang berpengaruh pada kapasitas simpang bersinyal serta membuat uraian sitematis dari teori - teori yang relevan dengan topik penelitian berdasarkan jurnal atau paper, buku, laporan skripsi, thesis maupun disertasi yang dituangkan dalam kajian pustaka.

3. Tahap ke-3 adalah tahap pra-pengumpulan data yang meliputi kegiatan penentuan jenis data yang digunakan, jumlah sample dari populasi data, instrument. waktu dan lokasi penelitian, kebutuhan tenaga survei serta mempersiapkan surat ke instansi pemerintah.

4. Tahap ke-4 adalah tahap pengumpulan atau collecting data. Tahap pengumpulan data merupakan kegiatan untuk mengumpulkan semua data yang diperoleh melalui survei lapangan mapun instansi pemerintah. 
5. Tahap ke-5 adalah ekstraksi atau penyaringan data.

6. Tahap ke-6 adalah input data dalam rumus analisis simpang bersinyal berdasarkan metode MKJI 1997.

7. Tahap ke-7 adalah tahap validasi. Tahap validasi adalah membandingkan panjang antrian dari hasil analisis dengan metode MKJI 1997 dengan panjang antrian dari hasil pengukuran di lapangan. Panjang antrian dari kedua hasil tersebut dibuat dalam bentuk grafik prosentase kumulatif.

\section{HASIL DAN PEMBAHASAN}

Penelitian dilakukan pada simpang Majapahit. Simpang tersebut memiliki 4 lengan simpang yang terdiri dari 2 lengan mayor dan 2 lengan minor. Perbedaan hasil perhitungan dengan metode MKJI 1997 ditunjukkan pada gambar 1.

Barat

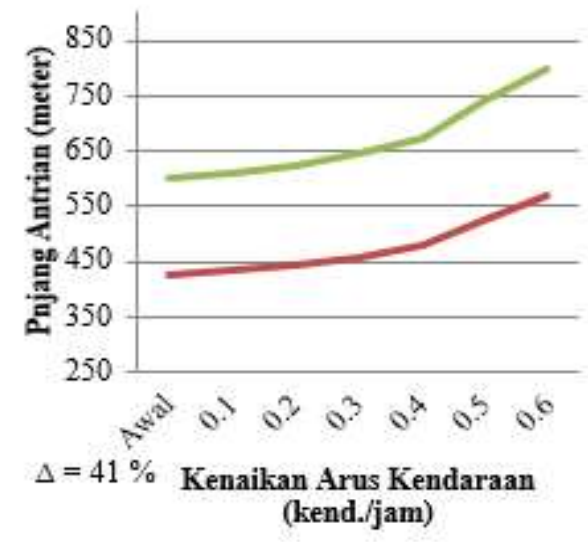

Timur

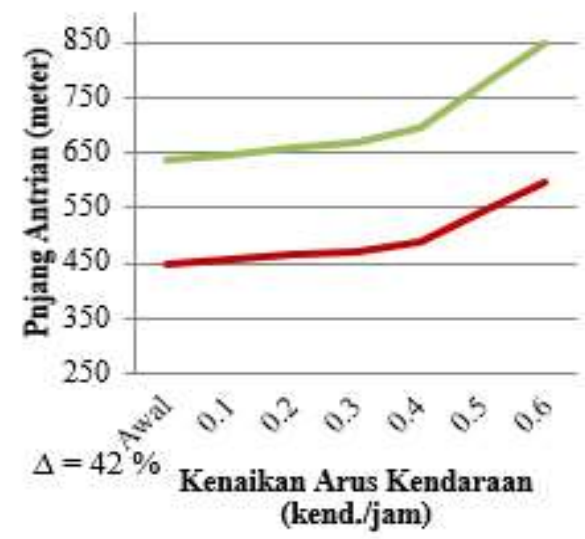

\section{Utara}

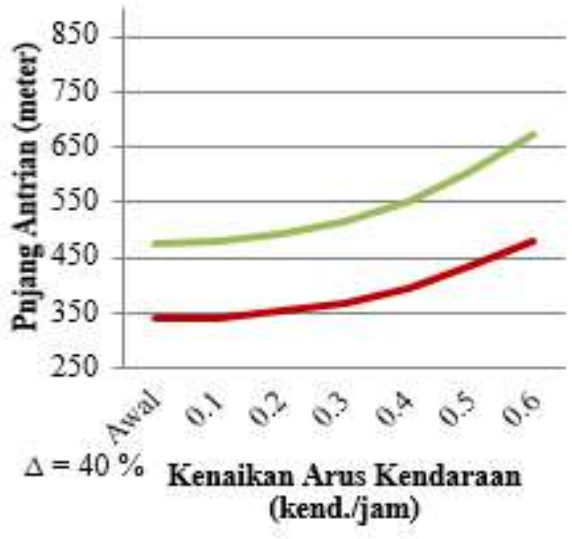

Selatan

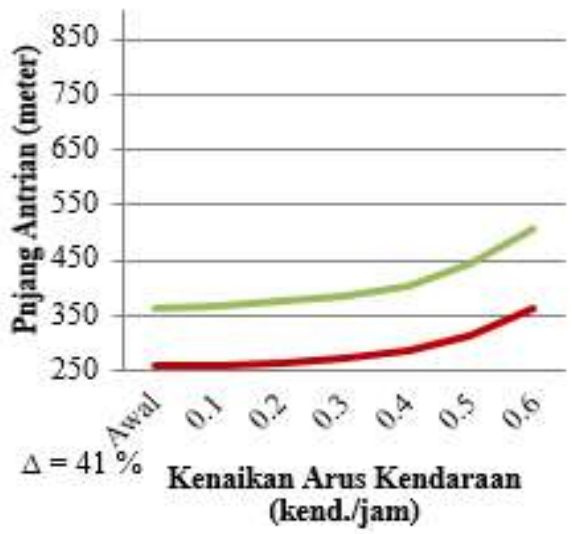

Gambar 1. Perbedaan Hasil Analisis MKJI 1997 (EMP Sepeda Motor 0.25) dengan Pengukuran Lapangan

Sumber : Hasil Analisis Peneliti, 1997

Dari Gambar 1, menunjukkan bahwa terdapat perbedaan yang cukup signifikan antara pengukuran lapangan dengan MKJI 1997, menggunakan EMP 0.25. Besarnya nilai perbedaan tersebut selanjutnya diuji secara statistic menggunakan uji t (T-Test) dengan SPSS. Hipotesis yang diujikan adalah sebagai berikut: 
HO = tidak terdapat perbedaan yang signifikan antara lapangan dengan MKJI 1997, nilai sig $>0.05$.

H1 = terdapat perbedaan yang signifikan antara lapangan dengan MKJI 1997, nilai sig < 0.05 .

Dari hasil uji beda menunjukkan bahwa terdapat perbedaan panjang antrian antara pengukuran lapangan dengan analisis secara makro (MKJI 1997). Perbedaan tersebut ditunjukkan dengan hasil nilai signifikansi pada semua lengan simpang yang bernilai $<0.05$. Hasil uji hipotesis tersebut juga menunjukkan bahwa hipotesis awal $(\mathrm{HO})$ ditolak dan hipotesi akhir (H1) diterima.

Sedangkan perbedaan hasil pengukuran di lapangan dengan metode MKJI 1997, menggunakan nilai EMP sepeda motor 0.15 ditunjukkan gambar 2 berikut ini.

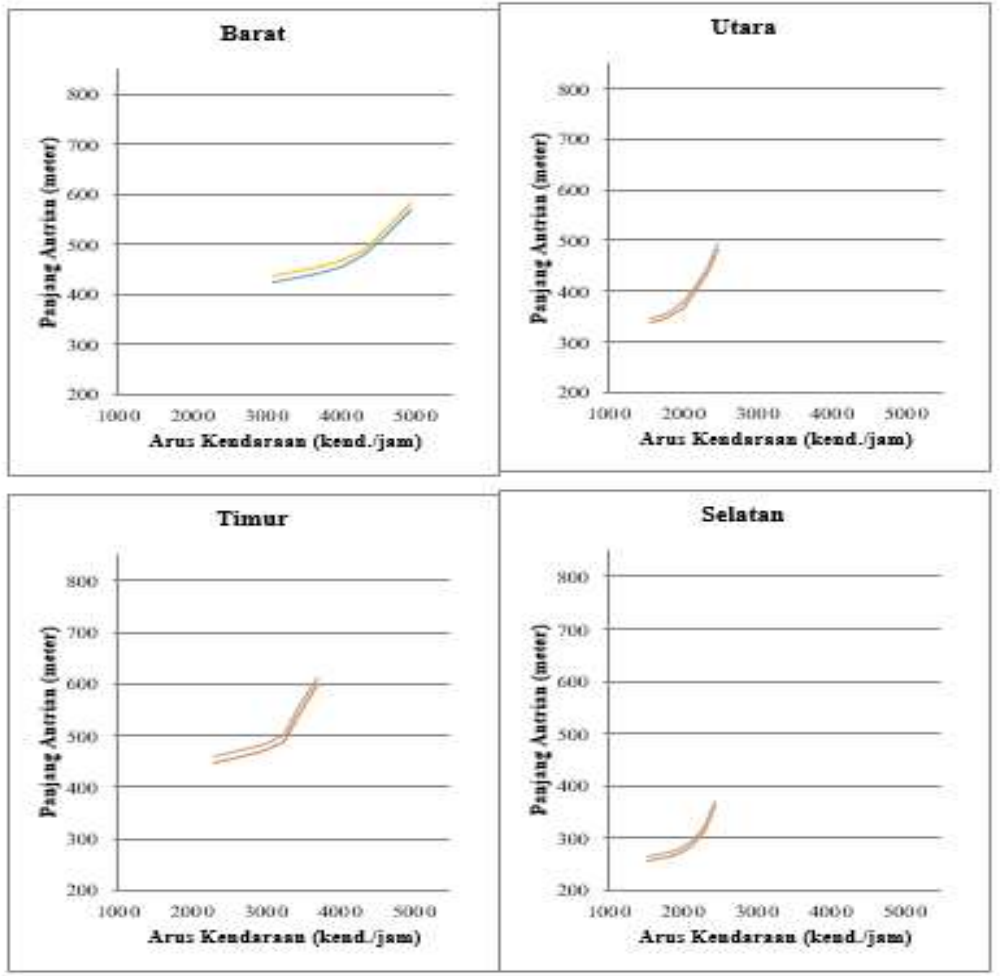

Gambar 2. Perbedaan Hasil Analisis MKJI 1997 (EMP Sepeda Motor 0.15) dengan Pengukuran Lapangan

Sumber : Hasil Analisis Peneliti, 1997

Dari gambar 2, terlihat bahwa model usulan menghasilkan panjang antrian yang mendekati panjang antrian lapangan. Hal tersebut secara grafis ditunjukkan dengan garis model usulan yang hampir berhimpit dengan lapangan. Besarnya nilai signifikansi antara model dengan lapangan diuji secara statistik dengan uji t sebagai tahap validasi model. Dari hasil uji t tersebut, menunjukkan bahwa nilai signifikansi model adalah sebesar $(<0.05)$. Karena nilai signifikansi yang dihasilkan di bawah 0.05, maka dapat disimpulkan bahwa tidak terdapat perbedaan yang signifikan antara model usulan perbaikan dengan pengukuran lapangan. Sehingga nilai konstanta arus jenuh sebesar 825 dan EMP sepeda motor sebesar 0.15 dijadikan sebagai usulan perbaikan MKJI 1997. 


\section{KESIMPULAN}

Sebagai manual atau guidelines yang digunakan untuk analisis, perencanaan dan perancangan lalulintas di Indonesia, maka perlu adanya pengkinian MKJI yang disesuaikan perkembangan kondisi lalulintas yang ada, baik dari sisi jumlah dan komposisi kendaraan bermotor, perubahan geometrik ruas maupun simpang, teknologi kendaraan, perubahan fungsi tata guna lahan, serta perubahan perilaku pengemudi. Pengkinian MKJI dapat dilakukan dengan merevisi konstanta arus jenuh dan EMP sepeda motor pada MKJI 1997. Nilai EMP akan mempengaruhi besarnya arus lalulintas. Semakin tinggi nilai EMP, maka arus yang dihasilkan juga semakin besar. EMP sepeda motor dipilih sebagai salah satu usulan perbaikan MKJI karena proporsi jumlah sepeda motor yang mendominasi di antara kendaraan yang lain. Dari hasil uji nilai EMP dari 0.15 - 0.19, maka EMP 0.15 adalah nilai yang memberikan hasil analisis yang paling mendekati lapangan.

\section{DAFTAR PUSTAKA}

Andriyanto, A., ( 2012 ), Simulasi Antrian Pintu Tol Dengan Menggunakan Pemrograman Komputer (Studi Kasus Pintu Tol Cililitan), Tesis Program Studi Magister Sistem dan Teknik Transportasi Jurusan IImu - IImu Teknik Program Studi, Universitas Gadjah Mada, 2012.

Aronsson, K.F.M., ( 2006 ), Speed Characteristics of Urban Streets Based on Driver Behaviour Studies and Simulation, Doctoral Thesis in Infrastructure Royal Institute of Technology Stockholm, Sweden 2006.

Beaulieu, M., Davis, K., Kieinger, D., Mizuza, K., Wright, D. dan Sanderson, A., ( 2007 ), A Guide to Documenting VISSIM - Based Microscopic Traffic Simulation Models, Washington State Transportation Centre, University of Washington, Juni 2007.

Bina Marga, ( 1997 ), Manual Kapasitas Jalan di Indonesia, Dinas PekerjaanUmum.

Boomlee, J., ( 2008 ), Calibration of a Macroscopic Traffic Simulation Model Using Enhanced Simutaneous Pasturbation Stochatic Appriximation Methodology, Transportation Research Board's 87 th Annual Meeting, Washington D.C, 2008.

Burghout, W. dan Wahlstedt, J., ( 2007 ), Hybrid Traffic Simulation of Adaptive Signal Control, The 86th Meeting of the Transportation Research Board, Transportation Research Record, Washington 2007.

Butar- Butar, M. dan Yamin, M., ( 2008 ), Pengunaan Simulasi UntukUNTUK Pemecahan Masalah Transportasi, Prosiding Seminar Ilmiah Nasional Komputer dan Sistem Intelijen Auditorium Universitas Gunadarma, Depok, 20-21 Agustus 2008 ISSN : 14116286, 2008.

Dmour, A. N., ( 2011 ), TarffSim: Multiagent Traffic Simulation, European Journal of Scientific ResearchISSN 1450-216X Vol.53 No.4, pp.570-575, Euro Journals Publishing, Inc, 2011. 
Irawati, I. dan Muldiyanto, A., ( 2012 ), Analisis EMP Sepeda Motor Menggunakan Metode Kapasitas Pada Simpang Bersinyal ( Studi Kasus Persimpangan Tlogosari Semarang ), ISBN 978-602-9029-74-2.

Khisty, C.J. dan Lall, B.K., ( 2003 ), Transportation Engineering: An Introduction, Penerbit Erlangga.Kotusevski, Gdan Hawick , K.A, ( 2009 ), A Review of Traffic Simulation Software, Computer Science, Institute of Information and Mathematical Sciences,Massey University, Albany, NS 102-904, Auckland, New Zealand, 2009.

Kotusevski, G. dan Hawick, K.A., ( 2009 ), A Review of Traffic Simulation Software, Technical Report CSTN-095, 23 Juli 2009.

Kusnandar, E., ( 2009 ), Pengkinian Manual Kapasitas Jalan Indonesia, Jurnal Jalan dan Jembatan, Vol.26, No.2, September 2009, Page 182 - 192.

Lee, J.B. dan Osbay, K., ( 2007 ), Calibration of Traffic Simulation Model Using Enhanced Simulation Perturbation Stochastic Approximation Methodology, Transportation Research Record, Journal of Transportation Research Board, 2007.

Manis, A. dan Hutami, S.T.S., ( 2011 ), Sistem Transportasi Bus Unad, Sistem Optimasi Industri 2, Hal. 16 - 22.

Mulyono, A., ( 2007 ), Model Monitoring dan Evaluasi Pemberlakuan Standart Mutu Perkerasan Jalan Berbasis Pendekatan Sistemik, Disertasi UNDP, 2007.

Munawar, A., ( 2007 ), EvaluasiPenggunaan Manual Kapasitas Jalan Indonesia 1997, Konferensi Nasional Teknik Sipil dan Jalan ke - 8, Jakarta, 4-5 September 2007.

Nguyen, T., ( 2011 ), A Flexible Model For Traffic Simulation and Traffic Signal Control Optimation, COMP 3740, Mei 2011.

Nigarnjanagool, S. dan DIA, H., ( 2005 ), Evaluation of A Dynamic Signal Optimization Control Model Using Traffic Simulation, IATSS Research. Vol.9 No.1, 2005.

Rahayu, G., Atmaja, P. dan Munawar, A., ( 2009 ), Analisis Arus Jenuh dan Panjang Antrian Pada Simpang Bersinyal : Studi Kasus di Jalan Dr. Sutomo - Suryopranoto, Yogyakarta, Jurnal Ilmiah Semesta Teknik, Vol.12, No.1, 99-108, Mei 2004.

Sari, R.M., (2005); Analisis Kapasitas Simpang terhadap Beroperasinya Terminal Giwangan, Teknik Sipil UGM, Yogyakarta, Tugas Akhir S1 (tidak dipublikasikan).

Siemens, (2012 ), Microschopic Traffic Simulation with VISSIM, Simulation of Multimodal Traffic Flow Made Easy.

Subandi, A., ( 2007 ), Ekivalen Mobil Penumpang Untuk Kendaraan Berat dan Sepeda Motor yang Belok Kanan pada Simpang Bersinyal, 2007, Tesis, ITB.

Suprapto, J., ( 2008 ), Statistik Teori dan Aplikasi, Penerbit Erlangga, 2008. 
Taplin, J., ( 2011 ), Simulation Models of Traffic Flow, Department of Information Management and Marketing University of Western Australia.

Tiwari, G., Fazio, J. dan Gaurav, S., ( 2007 ), Traffic Planning For Homogenous Traffic, Sadhana Vol.38, Part.4, August 2007, pp.309-329, Printed in India.

Wikrama, J.A.A.N.A., ( 2011 ), Analisis Kinerja Simpang Bersinyal ( Studi Kasus Jalan Teuku Umar Barat - Jalan Gunung Salak ), Jurnal Teknik Sipil, Vol.15, No.1, Januari 2011. 